\title{
Impairment of vasomotor reflexes in the fingertips of leprosy patients
}

\author{
J Swanson Beck, N C Abbot, P D Samson, C R Butlin, J M Grange, I A Cree, A Forster, \\ F Khan
}

\begin{abstract}
A method is described for eliciting fingertip vasomotor reflexes by inspiratory gasp and contralateral hand cold challenge. The results of the two tests are reproducible on replicate testing and, when taken together, have proved reliable for detection of impairment of autonomic reflexes in 10 newly registered leprosy patients who did not have any obvious deformity. Similar, but less severe, impairment of vasomotor reflexes was noted in a group of 10 fully treated, apparently cured ex-leprosy patients, none of whom showed clinically obvious neuropathy. Both the new patients and the ex-patients were significantly different from healthy contacts and from healthy Europeans, who were indistinguishable by this test. Evidence is presented suggesting that impairment of these vasomotor reflexes is mainly due to damage to the efferent pathway in the peripheral nerves. The method might prove valuable for investigation of early nerve damage in new patients or during reversal reactions in leprosy at a stage before irreversible damage is done.
\end{abstract}

Department of Pathology, University of Dundee, Dundee J Swanson Beck N C Abbot

I A Cree

Richardson Leprosy Hospital, Miraj, Maharashtra, India P D Samson C R Butlin

Department of Microbiology, National Heart and Lung Institute, London J M Grange

Department of Neurology, Dundee Royal Infirmary, Dundee

A Forster

Vascular Laboratory, Ninewells Hospital and Medical School, and Medical F Khan

Correspondence to: Professor J Swanson Beck, Department of Pathology, Ninewells Hospital and Medical School, Dunde DD1 9SY, UK.

Received 17 July 1990 and in revised form 26 and in revised Accepted 5 April 1991
Much of the long term disability of leprosy stems from the neuropathy which may cause permanent damage to the peripheral nerves, leading to serious sensory loss with the danger of trophic ulceration, or paralysis of motor function and secondary deformity. The development of this neuropathy is sometimes clinically apparent with swollen painful nerves, ${ }^{1}$ but often the onset is insidious and much permanent damage can occur ${ }^{2}$ before there are clinical indications to start antiinflammatory treatment. ${ }^{3}$ Diagnosis by nerve biopsy is practicable, but this expensive approach is not commonly used for ethical reasons and the practical problems of using invasive techniques away from a referral hospital. In the field, clinical examination is used to search for impairment of somatic sensation or motor power, but the methods are relatively insensitive and not very objective. Nerve conduction studies can provide reliable information in impairment of conduction in the larger myelinated fibres in the peripheral nerves in clinical leprosy, ${ }^{45}$ but the techniques are intricate and highly skilled operators are required if reproducible results are to be obtained.

There is good evidence that leprosy patients may develop abnormalities of autonomic function, such as localised loss of sweating in apparently uninvolved skin distant from the skin plaques. ${ }^{36}$ The efferent pathway responsible for these autonomic functions is carried in small non-myelinated or poorly myelinated fibres in the peripheral nerves ${ }^{7}$ and these are particularly vulnerable to damage from the inflammatory infiltrate of leprosy neuropathy. Autonomic neuropathy has been extensively studied in diabetes ${ }^{89}$ and a range of tests has been developed for detection of several types of visceral autonomic impairment in this disease. ${ }^{10-12}$ Methods, such as the Valsalva manoeuvre and the cold pressor test, have been used to demonstrate visceral autonomic impairment in patients with long-established leprosy, ${ }^{13-15}$ but these methods are unlikely to be sensitive indicators of early peripheral nerve disorders of autonomic function in leprosy, a disease where the neuropathy is focal and concentrated distally in the limb nerves. Accordingly, we have been interested in developing a method for the detection of the focal abnormalities that are commonly encountered in leprosy neuropathy.

Low et al ${ }^{16}$ proposed a new approach to the detection of neuropathic autonomic abnormalities by measuring the transient fall in fingertip blood flow after inspiratory gasp, on standing, during the Valsalva manoeuvre and following cold stimulation. They showed that these reflexes are lost in patients who have had avulsion of the corresponding spinal nerve roots. The clinical method they described had a rather high variability, but the approach has the important advantage of localising the defect to small skin regions. The methods of measurement of these reflexes has since been modified in Dundee to be sufficiently reproducible for use in clinical investigation and the reflexes have been shown to be impaired in Type I diabetics with clinical evidence of peripheral neuropathy ${ }^{17}$ and in some elderly people, perhaps as a consequence of ischaemic neuropathy (unpublished observations). The vasomotor reflexes can be temporarily inhibited by administration of prazosin (an $\alpha 1$ adrenoceptor antagonist), a drug which would be expected to paralyse the efferent process. ${ }^{18}$ This paper describes the use of a test of vasomotor reflexes based on laserDoppler measurements for identification of autonomic neuropathy in leprosy patients and assess its reproducibility. In our experience, the apparatus has been sufficiently robust for use in outlying clinics and the method could readily be adapted for use in field studies. 


\section{Patients and methods}

The methods were developed in studies on 10 healthy subjects in Dundee (aged (SD) 33.0 (8.18)) and then assessed at the Richardson Leprosy Hospital, Miraj, Maharashtra, India on 10 healthy subjects, 10 "contacts" frequently exposed to patients with leprosy, aged (SD) $35 \cdot 1$ (13.3), 10 newly diagnosed leprosy patients, aged $38.4(14 \cdot 3)$ and 10 subjects, aged $31.9(6.26)$ who had received curative treatment for leprosy many years previously. The newly registered patients were recruited for this method evaluation study because their abnormalities covered the wide range of clinical appearances seen in the disease: the diagnosis was confirmed histologically by biopsy of a skin plaque and classified as LL in three, BL in three, BT in three and indeterminate in one patient. No attempt was made to select a statistically representative sample of any particular category of leprosy patients. All subjects gave informed consent without coercion and the studies had been approved by the local Ethics Committee. All subjects were tested twice at an interval of one week.

\section{CLINICAL ASSESSMENT OF PERIPHERAL NERVE FUNCTION}

In the course of physical examination of the patients and controls, sensation in the upper limb was examined for integrity of touch (with von Frey hairs) and by pinprick: the median and ulnar nerves were palpated for enlargement. The physiotherapist assessed the strength of the various voluntary muscle groups in the upper limb. From this nonspecialist examination, the subjects were classified as having "severe" peripheral neuropathy if there was widespread abnormality in the various groups of tests, and as "partial" if there was either a) focal partial loss of sensation in the arm, forearm or hand, or b) a palpably swollen nerve, or c) convincing evidence of muscle weakness in some muscle groups. On this basis, the Dundee and Miraj controls did not show any abnormality of peripheral nerve function. Of the newlyregistered leprosy patients, five had "severe" and three had "partial" neuropathy.

MEASUREMENT OF FINGERTIP SKIN BLOOD FLOW Blood flow over the pulp of the distal phalynx near the fingertip was measured with a laserDoppler flowmeter (Model PF2, Perimed, Stockholm, Sweden) with machine settings of "gain, 3; band width, $12 \mathrm{KHz}$; time constant, $0.2 \mathrm{~s}$; artefact filter, off'. The laser-Doppler flowmeter measures movement of erythrocytes in the most superficial $1 \mathrm{~mm}$ of skin from changes in the wavelength in coherent light reflected out of the tissue. The instrument is internally standardised and gives an integrated measurement of microvascular blood flow (RBCflux, expressed in Volts), which is related directly to the product of the number of moving erythrocytes and their mean velocity at the measurement site. ${ }^{19-21}$ The fibre-optic sensor was attached to the fingertip by a probe holder fixed with double-sided adhesive tape, ensuring optimal alignment between sensor head and skin surface. The output signal was recorded continuously during the period of observation on a chart recorder (SE120, BBC Goetz Metrawatt, Austria) calibrated to a full scale deflection of $10 \mathrm{~V}$. The pulp of the finger was selected for investigation because its abundant arteriovenous anastomoses are under strict autonomic control. ${ }^{2223}$

\section{MEASUREMENT OF AUTONOMIC REFLEXES}

All subjects were seated with the forearm and hand at heart level in an ambient temperature of $26-29^{\circ} \mathrm{C}$, since near maximal vasodilatation of the microcirculation in the fingertips is induced in healthy subjects stabilised under these conditions.$^{18}$ Heating of the contralateral limb was not used lest this induced a sweat response which would complicate the interpretation of the tests. Each subject was seated quietly at the ambient temperature for at least 15 minutes before measurements were started.

In healthy subjects, the fingertip blood flow is not constant: there are two forms of periodicity, a rapid minor fluctuation in time with the arterial pulse (approximately $70 / \mathrm{min}$ ute) and a slower rhythm of greater amplitude, termed vasomotion, ${ }^{24}$ of 5-10 waves/minute, thought to be due to changes in vascular tone. When the normal subject is fully vasodilated, vasomotion becomes small relative to the arterial pulse effect. The "resting" fingertip blood flow was taken as the mean RBCflux value during a 3 minute observation period on an equilibrated subject.

The autonomic control of fingertip blood flow can be assessed by attempting to induce two simple vasomotor reflexes. The inspiratory gasp reflex is induced by the subject taking a sudden deep full inspiration, held for 10 seconds or until a minimum blood flow was recorded. In the normal subject there is a short lag period ( 2 to 3 seconds), a sharp rapid fall in blood flow velocity and then a quick return to the original level. This response is controlled by a spinal cord reflex with an unknown afferent (?baroreceptor) and a sympathetic

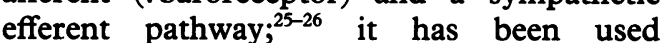
previously to test autonomic function. ${ }^{1627} \mathrm{~A}$ deep inspiratory "gasp" is required to trigger this reflex: accordingly we took care to ensure that all subjects-especially non English speaking Indian subjects-understood fully what was required of them before starting a test. The cold challenge reflex is provoked by quickly cooling the contralateral hand. The patterns of blood flow changes were similar to those seen in the gasp reflex. This spinal reflex depends upon afferent conduction of the impulses in the "cold" sensory fibres of the peripheral nerves and a sympathetic efferent pathway ${ }^{27} 28$ and it has also been used to test for disorders of autonomic function. ${ }^{16}$ In our experiments, the cold stimulation was invoked by plunging the contralateral hand into a bath of cold water (at or just below $15^{\circ} \mathrm{C}$ ): the water was stirred quite vigorously by the attendant to ensure a rapid fall in skin temperature on the subject's hand.

At each clinical examination, attempts were made to elicit both reflexes on each of the four fingers on one hand, usually the right: the same 
Figure 1 Diagram showing how the various indices are calculated from tracing of a vasomotor reflex.

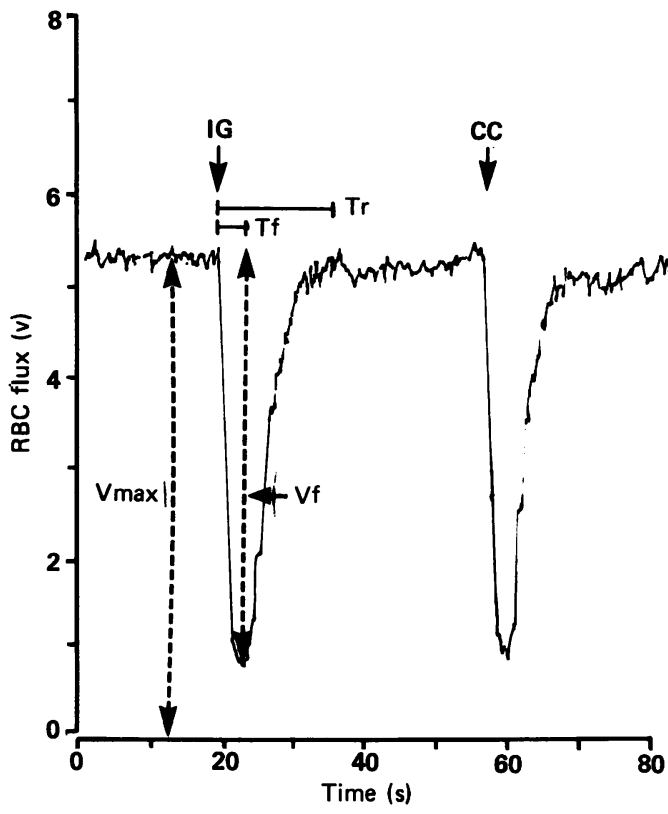

hand was used in replicate testing. To minimise variability in the gasp reflex due to misunderstanding from language difficulties, up to three deep gasps were elicted for the test on each finger and the largest response was used for subsequent analysis. During the cold challenge tests, the contralateral hand was dried and allowed to reheat before testing the response on another finger: this did not entail much delay in the tropical conditions at Miraj $\left(26-29^{\circ} \mathrm{C}\right)$.

\section{MEASUREMENT OF RESPONSE TO VASOMOTOR REFLEXES FROM TRACES}

Figure 1 shows the phases of the response and indicates how the measurements were made from the trace recording made at each experiment. Vmax indicates the prestimulation fingertip blood flow, $\mathrm{Vf}$ the extent of fall in signal during the reflex, $T f$ the time taken for the blood flow to fall to its lowest level and $\mathrm{Tr}$ the total response time ("duration") of the reflex. From these measurements, Vf/VMax indicates the proportionate fall in signal ("amplitude"), Vf/Tf the rate of fall ("velocity") and (Vf.Tr)/2 gives an estimate of the "magnitude" of response.
STATISTICAL ANALYSIS

The variation in measurements between fingers was assessed by the Student $t$ test and the reproducibility of replicate measurements on the same finger at one week's interval was analysed by the Bland and Altman method. ${ }^{29}$ Discriminant analysis was used to evaluate the relative separation between leprosy patients and healthy contacts, obtained by combining the results of the two vasomotor reflexes, to assess the potential clinical value of the various measurements that can be made from the tracings. The position of the optimal separating line is calculated and its Eigen value indicates the extent of separation achieved: the prediction table then indicates the number $(\%)$ of cases that have been classified correctly by the discriminant function. The calculations were performed on a microcomputer with the Statgraphics package (Release 3.0, STSC Rockville, MD, USA).

\section{REPRODUCIBILITY OF VASOMOTOR REFLEX MEASUREMENTS}

The differences between the measurements of various features of the vasomotor reflexes made at one week's interval on the healthy Dundee subjects, the healthy subjects in India who had had considerable exposure to leprosy and the fully treated leprosy patients are summarised in table 1. Analysis by the Bland and Altman technique $^{29}$ showed that the differences between replicates on the two groups of healthy people was relatively small and not significantly different from zero: for any parameter there was no association between the size of the measured character (mean of replicates) and that of the differences between replicates. Statistically significant differences (after correction for multiple testing) were seen between the replicates of abnormally low amplitude gasp responses and of abnormally slow velocity measurements in treated ex-patients, but the extent of this variability was small relative to the reduction in signal associated with the disease (table 1). Moreover, discriminant analysis of the clustering of the amplitude (Vf/ Vmax) of the gasp and cold reflexes in each group at one week's interval showed extensive overlap without statistical significance. It was concluded that the methods were sufficiently

Table 1 Means and differences (observation 2 - observation 1) between replicate measurements of vasomotor reflexes, one week apart on healthy Europeans and people exposed to leprosy and treated ex-patients. The findings on new patients at first contact are shown for comparison

\begin{tabular}{|c|c|c|c|c|c|c|c|c|c|c|c|c|c|c|}
\hline \multirow[b]{2}{*}{ Group } & & \multirow[b]{2}{*}{ Flux $(V)$} & \multicolumn{2}{|l|}{$V f(V)$} & \multicolumn{2}{|c|}{ Amplitude \% } & \multicolumn{2}{|l|}{$T f(\mathrm{sec})$} & \multicolumn{2}{|l|}{$\operatorname{Tr}(\sec )$} & \multicolumn{2}{|l|}{ Velocity } & \multicolumn{2}{|c|}{ Magnitude } \\
\hline & & & $G$ & $C$ & $G$ & $C$ & $G$ & $C$ & $G$ & $C$ & $G$ & $C$ & $G$ & $C$ \\
\hline $\begin{array}{l}\text { Healthy } \\
\text { European }\end{array}$ & $\begin{array}{l}\text { mean } \\
\text { SD } \\
\text { mean difference } \\
\text { SD }\end{array}$ & $\begin{array}{r}6.59 \\
1.46 \\
-0.06 \\
1.96\end{array}$ & $\begin{array}{l}5.34 \\
1.71 \\
0.56 \\
1.88\end{array}$ & $\begin{array}{l}4.77 \\
1.43 \\
0.31 \\
1.67\end{array}$ & $\begin{array}{c}79 \cdot 8 \\
13 \cdot 7 \\
3 \\
14 \cdot 1\end{array}$ & $\begin{array}{c}73 \cdot 4 \\
10 \cdot 8 \\
1 \\
15 \cdot 8\end{array}$ & $\begin{array}{l}7 \cdot 13 \\
2 \cdot 21 \\
1 \cdot 55^{\star} \\
2 \cdot 85\end{array}$ & $\begin{array}{r}6.03 \\
1.94 \\
-0.68 \\
3.55\end{array}$ & $\begin{array}{r}18 \cdot 73 \\
7 \cdot 82 \\
1 \cdot 27 \\
10 \cdot 58\end{array}$ & $\begin{array}{c}17 \cdot 95 \\
6 \cdot 96 \\
-2 \cdot 35 \\
16 \cdot 8\end{array}$ & $\begin{array}{r}0.81 \\
0.34 \\
-0.01 \\
0.03\end{array}$ & $\begin{array}{l}0 \cdot 88 \\
0 \cdot 37 \\
0 \cdot 01 \\
0 \cdot 04\end{array}$ & $\begin{array}{r}48 \cdot 76 \\
24 \cdot 41 \\
6 \cdot 47 \\
33 \cdot 01\end{array}$ & $\begin{array}{c}40.95 \\
15.9 \\
-4.61 \\
29.95\end{array}$ \\
\hline $\begin{array}{l}\text { Healthy } \\
\text { exposed }\end{array}$ & $\begin{array}{l}\text { mean } \\
\text { SD } \\
\text { mean difference } \\
\text { SD }\end{array}$ & $\begin{array}{l}5 \cdot 37 \\
1 \cdot 44 \\
0 \cdot 37 \\
2 \cdot 34\end{array}$ & $\begin{array}{r}4.61 \\
1.51 \\
-0.22 \\
2.06\end{array}$ & $\begin{array}{r}3.92 \\
1.45 \\
-0.39 \\
2.11\end{array}$ & $\begin{array}{r}84 \cdot 9 \\
9 \cdot 3 \\
4 \cdot 5 \\
18 \cdot 1\end{array}$ & $\begin{array}{r}73 \cdot 1 \\
14 \cdot 7 \\
2 \cdot 2 \\
22 \cdot 6\end{array}$ & $\begin{array}{r}7 \cdot 23 \\
2 \cdot 87 \\
-0 \cdot 77 \\
4 \cdot 42\end{array}$ & $\begin{array}{c}6.53 \\
4 \cdot 3 \\
-2 \cdot 63 \\
6.66\end{array}$ & $\begin{array}{c}27 \cdot 08 \\
20 \cdot 15 \\
3 \cdot 03 \\
25 \cdot 1\end{array}$ & $\begin{array}{c}21 \cdot 67 \\
12 \cdot 68 \\
-0.97 \\
21.9\end{array}$ & $\begin{array}{r}0.72 \\
0.34 \\
-0.01 \\
0.05\end{array}$ & $\begin{array}{l}0.74 \\
0.43 \\
0.02 \\
0.05\end{array}$ & $\begin{array}{c}61 \cdot 49 \\
41 \cdot 6 \\
2.9 \\
47.65\end{array}$ & $\begin{array}{r}41.06 \\
23.87 \\
-8.33 \\
45.93\end{array}$ \\
\hline $\begin{array}{l}\text { Treated } \\
\text { ex-patients }\end{array}$ & $\begin{array}{l}\text { mean } \\
\text { SD } \\
\text { mean difference } \\
\text { SD }\end{array}$ & $\begin{array}{r}4.46 \\
1.43 \\
-0.21 \\
1.66\end{array}$ & $\begin{array}{l}2.46 \\
1.7 \\
0.73^{\star} \\
1.56\end{array}$ & $\begin{array}{l}1.18 \\
1.5 \\
0.47 \\
1.82\end{array}$ & $\begin{array}{l}52 \\
30 \cdot 6 \\
18 \cdot 9^{\star} \\
29 \cdot 3\end{array}$ & $\begin{array}{r}25 \cdot 5 \\
30 \cdot 2 \\
9 \cdot 7 \\
30 \cdot 3\end{array}$ & $\begin{array}{r}9 \cdot 14 \\
6 \cdot 77 \\
0 \cdot 31 \\
11 \cdot 23\end{array}$ & $\begin{array}{r}7 \cdot 81 \\
6 \cdot 59 \\
-2 \cdot 89 \\
10 \cdot 06\end{array}$ & $\begin{array}{r}30 \cdot 31 \\
14 \cdot 57 \\
-4.03 \\
31 \cdot 09\end{array}$ & $\begin{array}{r}26 \cdot 2 \\
13 \cdot 22 \\
-3 \cdot 06 \\
25 \cdot 02\end{array}$ & $\begin{array}{l}0.44 \\
0.34 \\
0.02^{\star} \\
0.037\end{array}$ & $\begin{array}{l}0.31 \\
0 \cdot 26 \\
0.02^{\star} \\
0.03\end{array}$ & $\begin{array}{r}39.95 \\
27.51 \\
-5.52 \\
50.88\end{array}$ & $\begin{array}{r}19.72 \\
25.34 \\
1.64 \\
32.09\end{array}$ \\
\hline New patients & $\begin{array}{l}\text { mean } \\
\mathrm{SD}\end{array}$ & $\begin{array}{l}4 \cdot 36 \\
1 \cdot 72\end{array}$ & $\begin{array}{l}2 \cdot 11 \\
2 \cdot 14\end{array}$ & $\begin{array}{l}0.66 \\
2 \cdot 01\end{array}$ & $\begin{array}{l}46 \\
36 \cdot 8\end{array}$ & $\begin{array}{r}13 \cdot 5 \\
4 \cdot 7\end{array}$ & $\begin{array}{l}4 \cdot 8 \\
2 \cdot 12\end{array}$ & $\begin{array}{l}5 \cdot 18 \\
1 \cdot 78\end{array}$ & $\begin{array}{l}26 \cdot 43 \\
19 \cdot 24\end{array}$ & $\begin{array}{c}20 \cdot 75 \\
8 \cdot 6\end{array}$ & $\begin{array}{l}0.66 \\
0.41\end{array}$ & $\begin{array}{l}0.47 \\
0.35\end{array}$ & $\begin{array}{l}40 \cdot 14 \\
32 \cdot 7\end{array}$ & $\begin{array}{l}20 \cdot 87 \\
12 \cdot 45\end{array}$ \\
\hline
\end{tabular}

^Significantly different from zero $(p<0.05)$. 


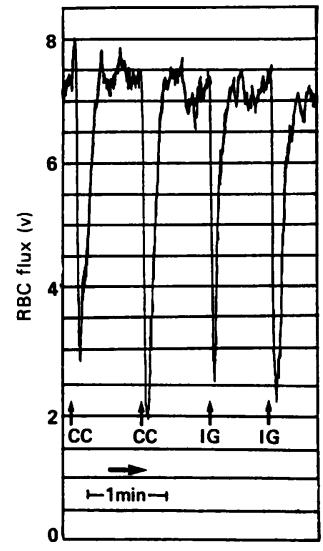

Figure 2 RBCflux measurement on $R$ middle finger of a healthy Indian subject showing normal brisk response to cold challenge (CC) and inspiratory gasp (IG). reproducible and reliable for clinical use on leprosy patients. Reproducibility assessments were not made on newly diagnosed leprosy patients, since they were started at their first visit on standard potent antimycobacterial therapy (Multidrug Therapy) which would be expected to modify the disease.

\section{Results}

FINGERTIP BLOOD FLOW CHANGES DURING VASOMOTOR REFLEXES IN HEALTHY SUBJECTS

The responses of healthy Dundee volunteers who have not had any known exposure to leprosy patients and the healthy contacts in Miraj were remarkably uniform. Figure 2 illustrates the record obtained from a normal Indian subject: shortly after provocation of either the gasp reflex or the cold challenge, there is a sharp fall in blood flow to a very low level followed by a rapid recovery to the prestimulation resting level.

\section{UNUSUAL PATTERNS OF BLOOD FLOW CHANGES DURING VASOMOTOR REFLEXES IN LEPROSY PATIENTS}

Some of the leprosy patients responded similarly to the healthy subjects, but most showed patterns not previously encountered in normal subjects. The patterns of abnormality encountered were: 1) Reduction in Vmax relative to that of clinically-normal fingertip skin (fig 3A); 2) Reduction in Vf after attempted elicitation of vasomotor reflex (fig $3 \mathrm{~A}$ )occasionally there is a complete absence of fall and rarely an inversion of response with rise of RBCflux after stimulation of either inspiratory gasp or cold challenge reflexes; 3 ) Slowing of velocity of onset of vasomotor reflex (fig 3A);4)
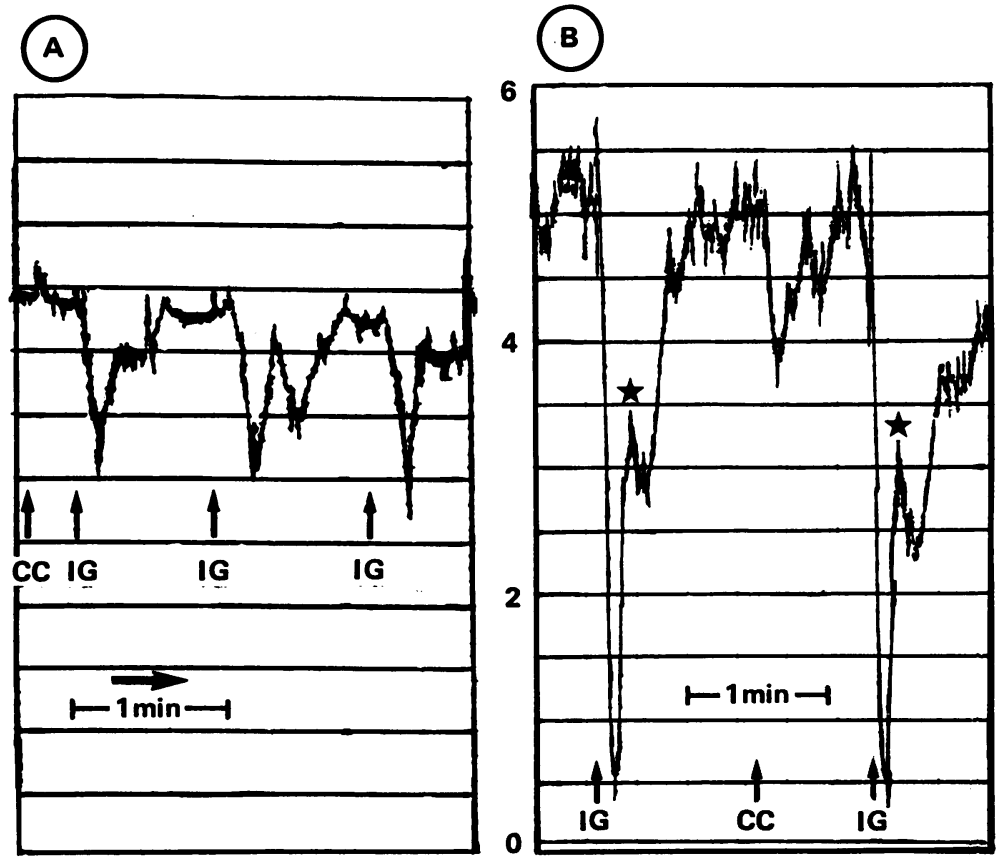

Figure 3 a) Vasomotor reflex test on newly diagnosed leprosy patient. The response to inspiratory gasp is reduced in amplitude, more gradual in onset and slower in recovery than that seen in a healthy subject. This patient failed to respond to the cold challenge. b) Treated ex-patient. The inspiratory gasp reflex is intact with rapid onset of almost complete cessation of blood flow, but recovery is delayed: the asterisk indicates a temporary hesitation in the slowed return of normal blood flow. Cold challenge is disproportionately affected.
Normal induction of reflex, but slowed recovery (fig 3B); 5) Impairment of response to cold challenge, with or without impairment of gasp reflexes (fig 3B)-no patient was seen with an intact cold reflex when the gasp reflex was severely impaired or absent.

There were no statistically significant differences between individual fingers in the hands of healthy subjects in Dundee or India at the first testing or subsequent testing.

Many newly diagnosed or previously treated leprosy patients showed marked differences between individual fingers within the hand in the extent of abnormality of vasomotor reflexes: it was not uncommon for the responses to be near normal in one finger and severely impaired or even absent in other fingers in the same hand. The more severely affected patients showed marked impairment of the responses in all fingers. There was no evidence of selective involvement of particular fingers nor were the abnormalities segregated in the territories of the major nerves (median or ulnar). There was no evidence of disturbance of somatic peripheral nerve function in either the Dundee or Miraj controls. The newly-registered leprosy patients with "severe" or "partial" somatic neuropathy showed more extensive disturbance of vasomotor reflexes than those with no abnormality of peripheral nerves on physical examination, but the numbers were too small for statistical analysis. The curatively-treated leprosy patients were reluctant to submit to an extended physical examination, so no comparison is available between autonomic and somatic peripheral nerve function in this group.

ASSESSMENT OF THE VALUE OF MEASUREMENTS OF VASOMOTOR REFLEX RESPONSES IN DETECTING DISTURBANCE OF AUTONOMIC FUNCTION IN THE PERIPHERAL NERVES OF LEPROSY PATIENTS

Figure 4 shows the relationship between measurements of the amplitude of responses to gasp and cold reflexes determined at the first visit in the four clinical groups. There was little difference between the healthy non-exposed subjects in Dundee (fig 4A) and healthy contacts in India (fig 4B), and both groups showed a large response in both reflexes. The newly diagnosed (fig 4C) and previously treated expatients (fig 4D) showed much diversity in response with the response to cold challenge often being more severely affected than that to gasp. Many patients showed a poor response in both tests: in the newly-registered patients, 22/ 40 fingers showed the absence of either or both gasp or cold reflexes, while the corresponding figure for the ex-patients was $14 / 40$, but this difference was not significant.

Table 2 summarises the results of discriminant analysis on the four major measurements from the traces using the mean value for each patient's hand (based on the observations on four fingers) in the various clinical groups. It is clear that amplitude (Vf/Vmax) gives very good separation of healthy people from newly-diagnosed or ex-leprosy patients. The calculated discriminant function for optimal separation between groups of healthy exposed people and 


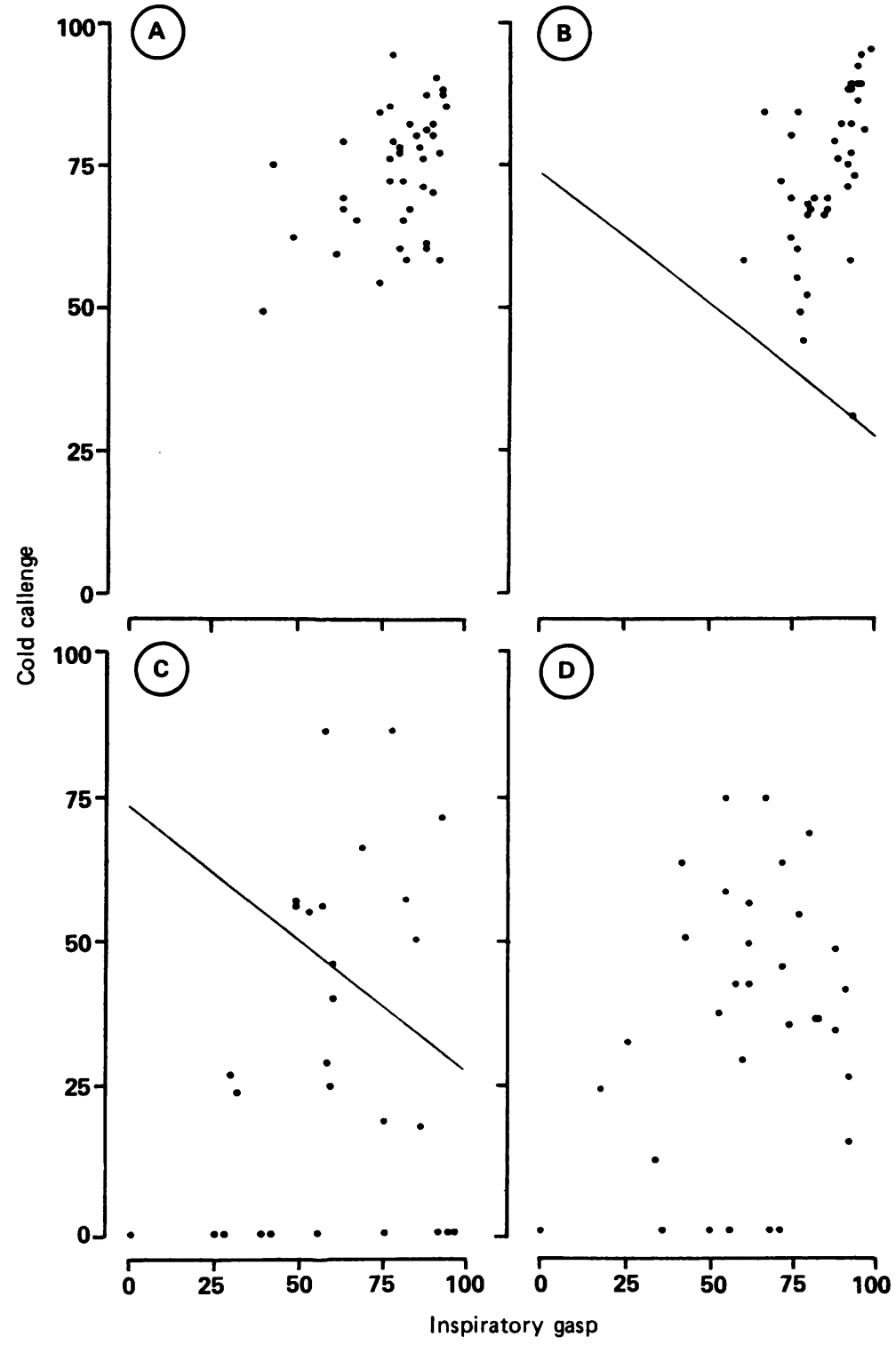

Figure 4 Scatter diagrams to show the relationship between amplitude of responses in inspiratory gasp and cold challenge vasomotor reflexes in all four fingers in one hand of a) healthy volunteers in Dundee, b) contacts of leprosy patients in Miraj, c) newlyregistered leprosy patients and d) treated, apparently healthy ex-leprosy patients. The line on panels $b$ ) and c) indicates the discriminant function for best separation of results of contacts from newly-registered patients using the mean value for each patient's hand. The zero points in panels c) and d) represent 13 and nine values respectively that showed absent responses to both gasp and cold challenge.

newly-diagnosed patients is shown in the appropriate panels of fig 4 .

Although the other measurements make some distinction between the diseased groups and the healthy subjects, the overlap is considerable and these features do not appear to be useful in diagnosing abnormality in the individual patients. Discriminant function analysis did not show any appreciable separation between healthy non-exposed Dundee subjects and healthy contacts in India for the four parameters measured.

\section{Discussion}

The technique developed by Low et $a l^{16}$ for detection of peripheral nerve autonomic dysfunction from abnormalities of fingertip vasomotor reflexes utilised direct heating of the hands to $34-35^{\circ} \mathrm{C}$ to induce local hyperaemia. Under these conditions the median proportionate fall in laser-Doppler signal was $45 \%$ after inspiratory gasp and $51 \%$ after cold challenge. For truly maximal vasodilatation, however, a sufficiently high core temperature is required to release central vasoconstriction tone with subsequent opening of arterio-venous anastomoses at the fingertips ${ }^{23}{ }^{30}$ and the warm blood entering the hand has an additional direct heating effect on the nutritional microcirculation. The resting blood flow achieved under these conditions is stable and has fewer spontaneous or vasomotive fluctuations. In practice, a small elevation of core body temperature can be achieved by contralateral warming when the ambient temperature is low, ${ }^{17}$ or by stabilising subjects at high ambient temperature. In this study, healthy subjects at an ambient temperature of $26-29^{\circ} \mathrm{C}$ showed a mean (SD) reduction in blood flow of 84.9 (9.3)\% with inspiratory gasp and of $73 \cdot 1$ $(14 \cdot 7) \%$ with cold challenge. These results compare well with those obtained with contralateral warming ${ }^{17}$ and are more consistent than those reported by Low et al. ${ }^{16}$ Our technique had poorer reproducibility in patients than in healthy people, but the methodological variability is small relative to the magnitude of the changes seen in disease.

From this study it is clear that leprosy patients may show several types of defects in finger tip vasomotor responses to inspiratory gasp or cold challenge. The commoner types of abnormality have been illustrated in this paper. It has been established that the defects in an individual finger are reproducible in repeated testing and that the overall pattern of response in the hands of the ex-patients did not change over the short period of observation in this study (up to one week). Certain abnormal responses can be readily measured (for example, the extent of fall in blood flow velocity, the rates of fall and recovery and the duration of slowed blood flow), but others such as the

Table 2 Summary of results of discriminant analysis to evaluate separation of mean values for each person's hand between healthy exposed subjects ("contacts") and either newly diagnosed leprosy patients or fully treated patients

\begin{tabular}{|c|c|c|c|c|c|c|c|c|}
\hline \multirow[b]{4}{*}{ Measurement } & \multicolumn{8}{|c|}{ Groups compared } \\
\hline & \multicolumn{4}{|c|}{ Exposed healthy $v$ new patients } & \multicolumn{4}{|c|}{ Exposed healthy $v$ ex-patients } \\
\hline & \multirow{2}{*}{$\begin{array}{l}\text { Eigen } \\
\text { value }\end{array}$} & \multirow[b]{2}{*}{ Pvalue } & \multicolumn{2}{|c|}{$\begin{array}{l}\text { Number "1/1 correctly } \\
\text { classified as }\end{array}$} & \multirow{2}{*}{$\begin{array}{l}\text { Eigen } \\
\text { value }\end{array}$} & \multirow[b]{2}{*}{ Pvalue } & \multicolumn{2}{|c|}{$\begin{array}{l}\text { Number } \% \text { correctly } \\
\text { classified as }\end{array}$} \\
\hline & & & Healthy & Abnormal & & & Healthy & Abnormal \\
\hline $\begin{array}{l}\text { Amplitude } \\
\text { Velocity } \\
\text { Duration } \\
\text { Magnitude }\end{array}$ & $\begin{array}{l}2 \cdot 83 \\
0 \cdot 137 \\
0.010 \\
0.566\end{array}$ & $\begin{array}{l}0.00001 \\
0.382 \\
0.929 \\
0.035\end{array}$ & $\begin{array}{c}10(100) \\
7(70) \\
3(30) \\
7(70)\end{array}$ & $\begin{array}{l}9(90) \\
5(62 \cdot 5) \\
5(62 \cdot 5) \\
6(75)\end{array}$ & $\begin{array}{l}2 \cdot 69 \\
1 \cdot 10 \\
0.054 \\
0.737\end{array}$ & $\begin{array}{l}0.00002 \\
0.0026 \\
0.656 \\
0.012\end{array}$ & $\begin{array}{c}10(100) \\
9(90) \\
7(70) \\
8(80)\end{array}$ & $\begin{array}{l}9(90) \\
9(90) \\
5(55 \cdot 6) \\
6(66 \cdot 7)\end{array}$ \\
\hline
\end{tabular}


biphasic recovery are essentially qualitative. It has not been possible to measure accurately the lag period between the stimulation of the reflex and the onset of an effective response, because of our inability to define the nature of the evoking stimulus: we do not yet know the precise extent of thoracic expansion necessary to trigger the inspiratory gasp reflex nor is it clear how far the temperature of the dermis around the cold receptors must fall for the cold challenge to be effective.

Disturbance of vasomotor reflexes was more common in newly-registered leprosy patients with evidence of somatic peripheral neuropathy than in those with apparently normal peripheral nerve function, but the difference observed in the relatively small numbers (10) of newly-registered patients recruited for validation of the clinical method was not statistically significant: in subsequent studies on 33 newly-registered patients we have shown that the vasomotor reflex abnormality was greatest in those with "severe" neuropathy, and least in those without clinical evidence of neuropathy ( $p<0.05$, unpublished observations). It is clear that there can be considerable differences between responses in individual digits of the hands of a leprosy patient when a constant evoking stimulation is applied to the contralateral hand (cold challenge) or to the thoracic cage (inspiratory gasp). Since there is no evidence, even in advanced leprosy, of damage to the spinal cord (where the vasomotor reflexes are coordinated), it must be concluded that the major defect must occur in the efferent pathway. It is well known that peripheral nerves are a common site of damage throughout the whole spectrum of leprosy. ${ }^{2}$ It is not possible to localise the site of damage from the anatomical distribution of the loss of function because of the complicated intraneural topology in the peripheral nerves with branching and fusion of fascicles in the median, ulnar and radial nerves. ${ }^{31}$ Nevertheless, the well established frequent occurrence of swelling in the peripheral nerves (for example, the ulnar nerve) in leprosy suggests that this will be the commonest site of involvement of the autonomic efferent fibres, but present evidence does not exclude the alternative possibility of involvement of the smaller branches (for example, digital nerves) or even damage in the dermal bundles of non-medullated fibres which may be abnormal in leprosy. ${ }^{32}$ It is even possible that the damage could lie in the sympathetic ganglia since there are older reports of their involvement in leprosy, ${ }^{33}$ but this has not been confirmed. Disorders of the afferent pathways probably contribute to a lesser extent to the disturbance of vasomotor reflexes. The greater reduction of the reflexes elicited by the cold challenge than by inspiratory gasp clearly demonstrated in this study suggests concurrent damage to the cold afferents in the peripheral nerves.

The demonstration of impairment of the vasomotor reflexes need not necessarily be the whole explanation for the disturbance of control of the finger tip circulation. In advanced leprosy, there is pathological evidence of damage to the dermal blood vessels ${ }^{340}$ and arteriographic evidence of narrowing of the medium-sized and smaller limb arteries. ${ }^{36-38}$ None of the patients reported in this paper were in the advanced stages of the disease or had clinically abnormal fingers: the mean resting finger tip blood flows were high and well within the normal range established in healthy Europeans with the same apparatus. ${ }^{39}$ The vasoconstrictive response to cold challenge was frequently more severely impaired than that to inspiratory gasp (fig 4) in both newly-registered and curatively-treated leprosy patients: the disparity between the responses to alternative methods for eliciting the reflex could not have arisen if the lesions were restricted to the vessel walls. We concluded that leprosy arteriopathy did not make any substantial contribution to the impairment of vasomotor reflexes in the patients reported in this paper.

It is hoped that the method described in this paper will provide a useful approach for serial studies in monitoring the individual patient for early subclinical evidence of neuropathy in reversal reactions, thereby making it possible to institute anti-inflammatory treatment while nerve damage is still potentially reversible. It should also be useful for monitoring nerve damage during clinical trials of new regimes for the treatment of leprosy.

We are grateful to LEPRA for generous financial suport and to Dr Waters of The Leprosy Mission who enabled NCA and JSB to visit Maharashtra. We wish to acknowledge the help and support we received from Dr D Jadhav and the many staff members at the Richardson Leprosy Hospital in Miraj who made the study possible. Dr R A Brown of the Department of Mathematical Sciences gave us valuable advice on the statistical
analysis of the results. The study would not have been possible analysis of the results. The study would not have been possible
but for the active cooperation of the many patients who participated in the study.

1 Pfaltzgraff REP, Bryceson A. Clinical Leprosy. In: Hastings RC, ed. Leprosy: Edinburgh: Churchill Livingstone, 1985:255-73.

2 Job CK. Nerve damage in leprosy. Int J Lep 1989;57:532-9.

3 Jacobson RR. Treatment. In: Hastings RC, ed. Leprosy. Edinburgh: Churchill Livingstone, 1985:53-87.

4 Dash MS. A study of the conduction velocity of sensory fibers of the ulnar nerve in leprosy. Int $J$ Lep 1967;35: 460-99.

5 Shetty VP, Mehta JN, Antia NH, Irani PF. Teased fibre study of early nerve lesions in leprosy and in contacts, with study of early nerve lesions in leprosy and in contacts, with
electrophysiological correlates. J Neurol Neurosurg Psyelectrophysiological corr
chiatry 1977;40:708-11.

6 Sehgal VN. Significance of the local sweat response in the diagnosis of leprosy. Dermatologica 1974;148:217-23.

7 McLeod JG. Autonomic dysfunction in peripheral nerve disease. In: Bannister R, ed. Autonomic failure. Oxford: Oxford University Press, 1985:607-23.

8 Thomas PK, Eliasson SG. Diabetic neuropathy. In: Dyck PJ, Thomas PK, Lambert EH, Bunge R, eds. Peripheral neuropathy. Philadelphia: Saunders, 1984:210-30.

9 Ewing DJ, Clarke BF. Diabetic autonomic neuropathy: present insights and future prospects. Diabetes Care 1986;9:648-65.

10 Levin AB. A simple test of cardiac function based upon the heart rate changes induced by the Valsalva maneuver. $\mathrm{Am}$ heart rate changes induced
$J$ Cardiol 1966;18:90-9.

11 Wheeler T, Watkins PI. Cardiac denervation in diabetes. BMJ 1973;4:584-6.

12 Ewing DJ, Campbell IW, Murray A, Neilson JMM, Clarke BF. Immediate heart-rate response to standing: simple test of autonomic neuropathy in diabetes. $B M J$ 1978;1:145-7.

13 Dabholkar VR, Gaitonde BB. A study of autonomic functions in leprosy. Lep Ind 1982;54:303-17.

14 Kyriakidis MK, Noutsis CG, Robinson-Kyriakidis CA, et al. Autonomic neuropathy in leprosy. Int J Lep 1983; 51:331-5.

15 Ramachandran A, Neelan PN. Autonomic neuropathy in leprosy. Ind J Lep 1987;59:405-13.

16 Low PA, Neumann C, Dyck PJ, Fealey RD, Tuck RR. Evaluation of skin vasometer reflexes by using laser Doppler velocimetry. Mayo Clin Proc 1983;58:583-92.

17 Khan F, Spence VA, Wilson SB, Abbot NC. Quantification
of sympathetic vascular responses in skin by laser Doppler 
flowmetry. Int J Microcirculation: Clin Exper 1991; 10:145-53.

18 Khan F, Struthers AD, Spence VA. The effect of prazosin on skin microcirculation as assessed by laser Doppler flowskin microcirculation as assessed by laser Dopp

19 Nilsson GE, Tenland T, Oberg PA. A new instrument for continuous measurement of tissue blood flow by light beating spectroscopy. IEEE Trans Biomed Eng 1980;27:12-19.

20 Nilsson GE, Tenland T, Oberg PA. Evaluation of a laser Doppler flowmeter for measurement of tissue blood flow. IEE Trans Biomed Eng 1980;27:597-604.

21 Holloway GA. Laser Doppler measurement of cutaneous blood flow. In: Rolfe P, ed. Non-invasive physiological measurement, vol 2. London: Academic Press, 1983: $219-49$.

22 Grant RT, Bland EF. Observation on arteriovenous anastomoses in human skin and in the bird foot with special

23 Hales JRS, Iriki M, Tsuchiya K, Kozama E. Thermally induced cutaneous sympathetic activity related to blood fow through capillaries and arteriovenous anastomoses. Pflug Arch 1978;375:17-24.

24 Salerud EG, Tenland T, Nilsson GE, Oberg PA. Rhythmical variation in human skin blood flow. Int J Microcirculation: Clin $\operatorname{Exp} 1983 ; 2: 91-102$.

25 Bolton B, Carmichael EA, Sturup G. Vaso-constriction following deep inspiration. J Physiol 1936;86:83-94

26 Gilliat RW. Vaso-constriction in the finger after deep inspiration. $J$ Physiol 1948;107:70-88.

27 Johnson RH, Spalding JMK. The nervous control of the circulation and its investigation. Disorders of the autonomic circulation and its investigation. Disorders of the

28 Sinclair D. Motor nerves and reflexes In: Jarrett A, ed. The physiology and pathophysiology of the skin, vol 2. The nerves and blood vessels. London: Academic Press, 1973:475-508. 29 Bland JM, Altman DG. Statistical methods for assessing agreement between two methods of clinical measurement. Lancet 1986;i:307-10.

30 Bini G, Hagbarth KE, Hynninen P, Wallin PG. Thermoregulatory and rhythm generating mechanisms governing the sudomotor and vasoconstrictor outflow in human cutaneous nerves. J Physiol 1980;306:537-52.

31 Sunderland S. Intraneural topology of radial, median and ulnar nerves. Brain 1945;68:243-99.

32 Karanth SS, Springall DR, Lucas S, Levy D, Ashby P, Levene MM, Polak JM. Changes in nerves and neuropeptides in skin from 100 leprosy patients investigation by immunocytochemistry. J Pathol 1989;157:15-26.

33 Ermakova N. Studies in leprosy: the central sympathetic and peripheral nervous system. Int J Lep 1936;4:325-35.

34 Turkel SB, Van Hale HM, Rea TH. Ultrastructure of the dermal microvasculature in leprosy. Int J Lep 1982; 50:164-71.

35 Burchard G-D, Bierther M. An electron microscopic study of the small cutaneous vessels in lepromatous leprosy. In $J$ Lep 1985;53:70-4.

36 Yadav SS. Arteriographic evaluation of vascular changes in leprosy. Angiology 1978;29:17-2

37 Chopra JS, Kaur S, Murthy JMK, Kumar B, Radhakrishnan K, Suri S, Sawhney BB. Vascular changes in lepros and its role in the pathogenesis of leprous neuritis. Lep Ind 1981;53:443-53.

38 Agrawal BR, Agrawal RI. Arteriography in Leprosy. Int J Lep 1981;57:138-45.

39 Khan F. The sympathetic control of skin blood flow and its significance in thermoregulation. ( $\mathrm{PhD}$ Thesis), 1990 University of Dundee. 